\title{
Neonatal Death Rates: Lack of Equal Access to Hospital Obstetric Service and Intensive Therapy
}

\author{
Rosângela Aparecida Pimenta Ferrari ${ }^{*}$, Maria Rita Bertolozzi², Edmarlon Girotto ${ }^{3}$, \\ José Carlos Dalmas ${ }^{4}$, Alexandrina Aparecida Maciel Cardelli ${ }^{1}$ \\ ${ }^{1}$ Department of Nursing, Health Sciences Center, State University of Londrina (UEL), Londrina, Brazil \\ ${ }^{2}$ Department of Public Health, School of Nursing, University of São Paulo (EEUSP), São Paulo, Brazil \\ ${ }^{3}$ Department of Pharmacy, Health Sciences Center, State University of Londrina (UEL), Londrina, Brazil \\ ${ }^{4}$ Department of Statistics, Centre for Mathematical Sciences, State University of Londrina (UEL), Londrina, \\ Brazil \\ Email: "ropimentaferrari@uel.br, mrbertol@usp.br, eddieuel@yahoo.com.br, dalmas@uel.br, \\ macielalexandrina@gmail.com
}

Received 19 January 2016; accepted 4 April 2016; published 7 April 2016

Copyright (C) 2016 by authors and Scientific Research Publishing Inc.

This work is licensed under the Creative Commons Attribution International License (CC BY).

http://creativecommons.org/licenses/by/4.0/

c) (i) Open Access

\section{Abstract}

Aim: To identify the association between access to obstetric and neonatal hospital service and neonatal death rates. Method: Quantitative and retrospective research retrieved from Declaration of Live Newly-born Children; Declaration of Death; Investigation Chart on Municipal Child Mortality, between 2000 and 2009, at the Nucleus of Information on Mortality Rates. The population studied comprised 537 neonatal deaths and mothers with residence in the municipality, and investigated by the work team of the Committee for the Investigation of Mother-Child Deaths. Data were analyzed in Epi Info $2002{ }^{\circledR}$ computer program and the Statistical Package for the Social Sciences ${ }^{\circledR}$ was used. Chi-square Test and Fischer's Exact Test were applied at $p<0.05$. Results: $63.7 \%$ of 537 neonates were born in hospitals with maternities and neonatal intensive therapy unit; $60.7 \%$ weighed $\leq 1.500$ grams; $76.7 \%$ had a pregnancy age of $\leq 36$ weeks; $73 \%$ died of asphyxia in the $1^{\text {st }}$ minute and $73.5 \%$ died during the perinatal period. Throughout the ten years of analysis, access to hospital obstetric service without NITU reduced death rate from $25 \%$ in 2000 to $6.8 \%$ in 2009 . There was a significant statistical association between place of delivery and maternal socio-demographic variables (maternal age bracket $p=0.028$; schooling $p=0.000$; family income $p=$ 0.000); occupation $p=0.000$ ) and neonatal variables (race/skin color $p=0.007$; type of delivery $p$ $=0.000$; weight at birth $p=0.000$; pregnancy age $p=0.000$ and Apgar Score 1 st minute $p=0.000$ and Apgar Score $5^{\text {th }}$ minute $p=0.007$ ). Conclusion: Although the municipal government provides obstetric services and specialized neonatal care, this right is not extensive to all; gaps at different ${ }^{*}$ Corresponding author.

How to cite this paper: Ferrari, R.A.P., Bertolozzi, M.R., Girotto, E., Dalmas, J.C. and Cardelli, A.A.M. (2016) Neonatal Death Rates: Lack of Equal Access to Hospital Obstetric Service and Intensive Therapy. Open Journal of Obstetrics and Gynecology, 6, 259-267. http://dx.doi.org/10.4236/ojog.2016.65033 
levels in mother-child care should be identified to reduce neonatal deaths.

Keywords

Accessibility to Health Services, Neonatal Mortality, Gynecology and Obstetrics Hospital Unit,
Neonatal Intensive Therapy Unit

\section{Introduction}

In its section on health, the Brazilian Federal Constitution underscores that access to services provided by the Brazilian Health Service (SUS in Portuguese; henceforth BHS) should be available to all, together with preventive and curative actions, individual and collective, necessary for each case, at all levels of complexity. Although warranted integrality was a great progress in public health policy, it had become a great challenge to break through the unequal access to technologies in the country [1].

On the other hand, throughout several decades, public policies were deployed, with great improvements in mother-child assistance; an increase in income and a decrease in social disparities and differences, greater availability to basic sanitation, more schooling years, reduction of fertility rates and decrease in child mortality rates [1] [2]-[4].

In spite of such progress, neonatal mortality still persists. In most cases, it may be avoided by acknowledging maternal requirements within primary health care and by upgrading professional attendance with interventions to reduce the high number of deaths. These activities comprise family planning, pre-natal assistance, follow-up during delivery, humanized birth, assistance to the newly born in the birth room and in the neonatal unit, puerperal follow-up and a support network of mother-child reference and counter-reference services [1] [5]-[9].

Although child mortality coefficient has decreased from 120.7/1000 live births in 1970 to 19.9/1000 LB in 2010, neonatal mortality coefficient remains high, 13.6/1000 LB (68.0\%). In fact, perinatal causes are potentially avoidable through access to qualified health services for the control of maternal diseases and complications in pregnancy and delivery [2]-[4] [6] [10].

Current research identifies the association between access to obstetric and neonatal hospital service and mortality rates of recently-born infants. As gaps ranging between primary care and high complexity attention within health service are identified and adjusted, quality in mother-child assistance may be guaranteed. The Millennium Development Goals, namely, the $4^{\text {th }}$ on the reduction of child mortality and the $5^{\text {th }}$ on improvement the mother's health, will be consequently attained.

\section{Methods and Materials}

Current quantitative and retrospective (2000-2009) analysis retrieves data from the following documents published by the Ministry of Health: Declarations of Live Births; Death Certificates and Investigation Charts on Child Mortality belonging to the Municipal Committee for the Prevention of Mother and Child Mortality of a municipality with approximately 515,000 inhabitants in the northern region of the state of Paraná, Brazil.

Its health service is provided by 54 Basic Health Units within the urban and rural areas, urgency and emergence ambulance service, laboratories and first aid attendance. Hospital service comprises private and public care in small, medium and big-sized hospitals, with 1889 beds, of which 1344 are exclusively for patients attended by the BHS. Further, 311 beds are exclusive of mother-child care of the municipality and the surrounding region.

There are also four hospitals that attend pregnant women with low and medium pregnancy risks: a government-run hospital with 40 beds and three private ones with 63 beds. There are also two hospitals for medium and high risk pregnancy, with a Neonatal Intensive Therapy Unit (NITU) and Pediatric Intensive Therapy Unit (PITU): the government-run hospital has 25 obstetric beds, 17 neonatal beds (7 in NITU and 10 ICU) and 5 beds for PITU; the philanthropic hospital has 27 obstetric beds (19 for BHS patients) and 10 beds for the Neonatal and Pediatric Intensive Therapy Unit, of which 7 are also for BHS patients.

Further, 793 less-than-one-year-old children died during the 10-year period focused in current study. Ten children were excluded: one did not reside in the municipality; no information was forwarded with regard to the 
others (four in 2000 and six between 2001 and 2003), totaling 783 children deaths. Current study includes 537 (68.6\%) neonatal deaths and the mothers who resided in the rural or urban areas of the municipality, and analyzed by the Committee.

Data were retrieved between March and July 2010 by the processing of the Committee's data charts which contain all information of the mothers' history obtained from the places where pre-natal follow-up and delivery took place, Declaration of Live Births and Death Certificates.

Variables in current study comprised mothers' characteristics (age-bracket, schooling, family earnings, profession, marital situation, and residence area) and those of the new-born children (race/color, sex, type of birth, weight at birth, pregnancy age, Apgar for the $1^{\text {st }}$ and $5^{\text {th }}$ minute, transference to another hospital after delivery, place of delivery, place of death and causes of death).

Data were analyzed in Epi Info $2002^{\circledR}$ computer program and the Statistical Package for the Social Sciences ${ }^{\circledR}$ was used and Chi-square Test and Fischer's Exact Test were applied at $p<0.05$. Current analysis was authorized by the Directory in Health Care of the municipality, n.843/2009, CAAE n. 0044.0.196.000-09/843/2009.

\section{Results}

Data showed that 342 (63.7\%) out of 537 neonatal births occurred in hospitals with maternity and NITU; 36.3\% (176) of births were delivered in institutions without NITU and 3.5\% (19) at home or in transit.

Figure 1 demonstrates that during the 10 years focused in current study, attendance in hospitals with obstetric assistance but without NITU decreased from $25 \%$ in 2000 to $6.8 \%$ in 2009. Decrease from $21.1 \%$ to $5.3 \%$ has also been reported for births at home and in transit, respectively. Deliveries in the home, with death during the neonatal period, were not registered in 2001 and 2004 only.

Most socio-demographic variables of the mother revealed a statistically significant association $(p<0.05)$ to the place of birth, excepting marital status $(p=0.078)$. Table 1 registers that women within the $20-27$ and $\geq 28$ years age brackets reported with greater frequency (52.5\%) to hospitals with obstetric attendance and NITU, when compared with 12 - 19 year-old females (12.1\%). More than half (2.2\%) of births at home (3.5\%) occurred among women within the $12-27$ year-old age bracket. Table 1 shows that most women with $>8$ years schooling (45.6\%) were attended by hospitals with maternity and NITU, or rather, twice the amount when compared with those with similar schooling, who were attended by hospitals with maternity but without specialized neonatal assistance $(21.2 \%)$. No birth occurred either at home or in transit with women with $\geq 12$ years of schooling. Further, $37.1 \%$ of women with family income $>1$ minimum wage were attended in hospitals with NITU, whereas $17.4 \%$ gave birth in obstetric hospitals without NITU. Moreover, $51.4 \%$ of births at home or in transit occurred with females with family income $<2$ minimum wages. Table 1 also demonstrates that hospital attendance with obstetric and specialized assistance occurred among women (31.3\%) with and without income from the exercise of a profession (31\%), although hospitals with obstetric assistance without NITU were preferred by women

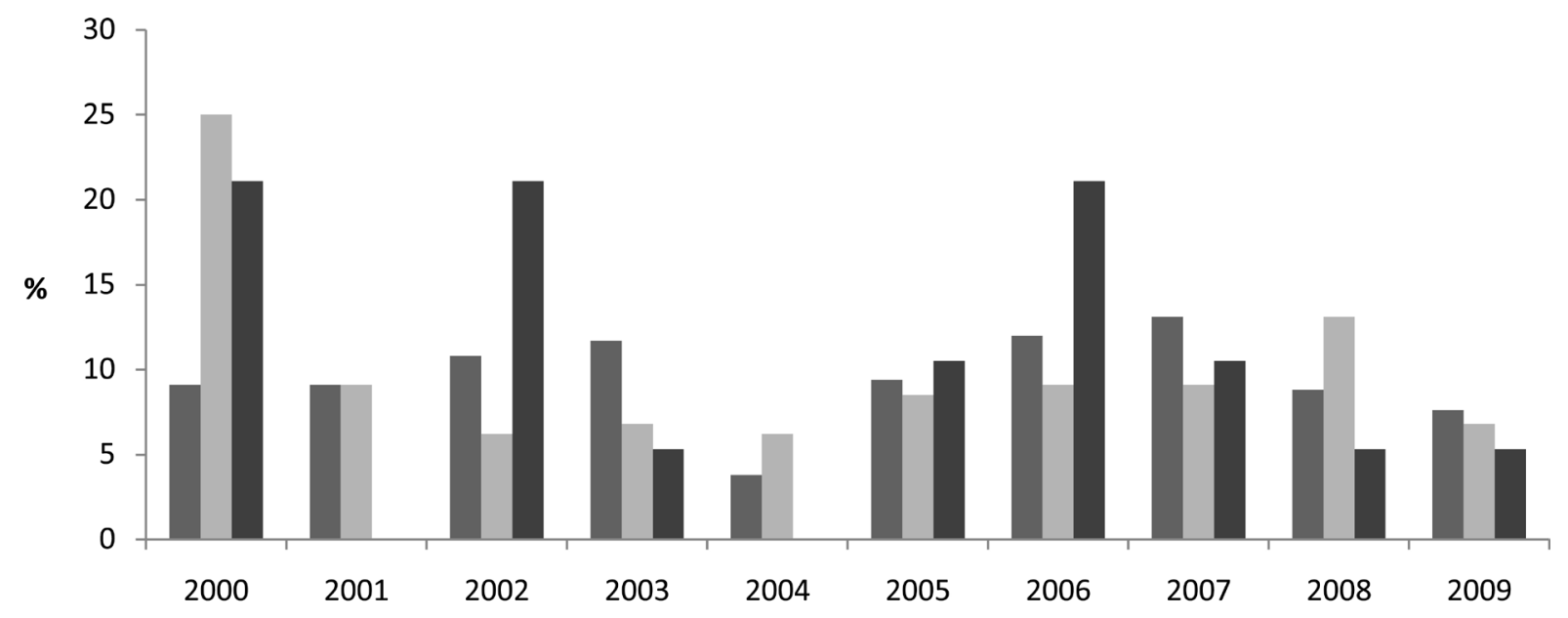

- Hospital with maternity and NITU Hospital with maternity without NITU $\square$ Delivery at home/in transit 
Table 1. Characteristics of the mother according to age bracket, schooling, family income, occupation, marital status and region of residence, related to the place of delivery. Londrina PR Brazil, 2000-2009.

\begin{tabular}{|c|c|c|c|c|c|c|c|}
\hline \multirow{4}{*}{ Characteristics of the mother ${ }^{\mathrm{a}}$} & \multicolumn{6}{|c|}{ Place of delivery } & \multirow{4}{*}{$\begin{array}{c}\text { Value } \\
p^{\mathrm{d}}\end{array}$} \\
\hline & \multicolumn{2}{|c|}{ Hospitals with NITUb } & \multicolumn{2}{|c|}{ Hospitals without NITU ${ }^{c}$} & \multicolumn{2}{|c|}{ Home/In transit } & \\
\hline & $\mathbf{n}$ & $\%$ & $\mathbf{n}$ & $\%$ & $\mathbf{n}$ & $\%$ & \\
\hline & 342 & 63.7 & 176 & 32.8 & 19 & 3.5 & \\
\hline \multicolumn{8}{|l|}{ Age bracket (years) } \\
\hline $12-19$ & 65 & 12.1 & 49 & 9.1 & 4 & 0.7 & \multirow{3}{*}{0.028} \\
\hline $20-27$ & 129 & 24.0 & 68 & 12.7 & 8 & 1.5 & \\
\hline$\geq 28$ & 148 & 27.5 & 59 & 11.0 & 6 & 1.0 & \\
\hline \multicolumn{8}{|l|}{ Schooling (years) } \\
\hline$\leq 7$ & 96 & 17.8 & 60 & 11.2 & 8 & 1.4 & \multirow{3}{*}{0.000} \\
\hline $8-11$ & 161 & 30.0 & 102 & 19.0 & 10 & 1.9 & \\
\hline$\geq 12$ & 84 & 15.6 & 12 & 2.2 & - & - & \\
\hline \multicolumn{8}{|l|}{ Family income $^{e}$} \\
\hline $1-2$ & 137 & 25.5 & 68 & 12.7 & 9 & 1.8 & \multirow{2}{*}{0.000} \\
\hline$\geq 3$ & 104 & 19.4 & 53 & 9.9 & 2 & 0.4 & \\
\hline \multicolumn{8}{|l|}{ Occupation } \\
\hline Waged & 168 & 31.3 & 70 & 13.0 & 11 & 2.1 & \\
\hline Non-waged & 166 & 31.0 & 104 & 19.4 & 7 & 1.3 & 0.000 \\
\hline \multicolumn{8}{|l|}{ Marital status } \\
\hline With partner & 289 & 53.8 & 140 & 26.1 & 12 & 2.2 & 0.078 \\
\hline Without partner & 49 & 9.1 & 32 & 6.0 & 6 & 1.1 & \\
\hline \multicolumn{8}{|l|}{ Area of residence } \\
\hline Downtown & 47 & 13.7 & 20 & 11.4 & 5 & 26.3 & \\
\hline East & 59 & 17.3 & 19 & 10.8 & 1 & 5.3 & \\
\hline West & 69 & 20.2 & 33 & 18.7 & 1 & 5.3 & 0.057 \\
\hline North & 76 & 22.2 & 55 & 31.2 & 5 & 26.3 & \\
\hline South & 75 & 21.9 & 37 & 21.0 & 4 & 21.0 & \\
\hline Rural & 16 & 4.7 & 12 & 6.8 & 1 & 5.3 & \\
\hline
\end{tabular}

${ }^{\mathrm{a}}$ All percentages exclude unknown information; ${ }^{\mathrm{b}}$ Hospitals with Maternity and Neonatal Intensive Therapy Unit (NITU); ${ }^{\mathrm{c}}$ Hospitals with Maternity and without Neonatal Intensive Therapy Unit (NITU)); ${ }^{\mathrm{d}}$ Value of $p$ with regard to Pearson's chi-test; ${ }^{\mathrm{e}}$ Minimum wage in the state of Paraná, Brazil, calculated for each year, between 2000 and 2009, following the Instituto Paranaense de Desenvolvimento Econômico e Social (IPARDES).

without income (19.4\%), when compared with those with income (13\%). Marital status did not affect the place of child birth. More than half (53.8\%) had a partner and birth occurred in a hospital with maternity and NITU, whereas only $26.1 \%$ were attended by an obstetric hospital without NITU. With regard to place of residence and place of birth, females residing in the countryside (41.4\%), followed by those living in the northern region of the municipality (40.4\%) preferred less the hospitals with obstetric service and NITU when compared to those living in the eastern (74.7\%), western (67\%) and central (65.3\%) regions, closer to school-university facilities.

Table 2 shows the statistical association between the characteristics of the newly born/delivery and the place of birth $(p<0.01)$, excluding gender $(p=0.221)$ and transference of the neonate $(p=0.333)$. Further, 85.8\% of neonates were white and $54.7 \%$ were born in hospitals with obstetric assistance and NITU. These features are similar for mixed race neonates. Contrastingly, Negro, Asiatic and Indigenous neonates were practically all born in government-run obstetric hospitals without NITU. Table 2 also reveals that Caesarean section was somewhat more frequent than vaginal birth in hospitals with obstetric assistance and NITU (32.2\%) than in those without NITU (16.6\%). Almost half of newly born babies weighing $\leq 1.500$ grams $(45.8 \%)$ and less than 31 weeks of pregnancy (45.2\%) were born in hospitals with maternity and NITU, although $12.5 \%$ and $11.2 \%$ were respec- 
tively born in hospitals without NITU. Neonates weighing $\geq 2500$ grams $(14.3 \%)$ and with pregnancy age $\geq 37$ weeks had similar percentages. Almost 70\% of neonates delivered at home or in transit (3.5\%) weighed less than 1500 grams. Slightly more than half $(51.2 \%)$ of newborns of all births in hospitals with maternity and NITU (63.7\%) had an Apgar score in the $1^{\text {st }}$ minute $<7$, whereas in the $5^{\text {th }}$ minute it came down to $29.6 \%$, or rather, a $57.8 \%$ decrease. Reduction was also reported in hospitals with maternity and without NITU (68.3\%), or rather, from $21 \%$ in the $1^{\text {st }}$ minute to $14.3 \%$ in the $5^{\text {th }}$ minute. Contrastingly, asphyxia (Apgar score $\leq 6$ ) prevailed in the $1^{\text {st }}$ and $5^{\text {th }}$ minute among births at home or in transit (Table 2). After birth, $25.5 \%$ of neonates were transferred

Table 2. Characteristics of newborns according to race/color, gender, type of delivery, weight at birth, pregnancy age, Apgar score and transference of newborn, related to place of birth. Londrina PR Brazil, 2000-2009.

\begin{tabular}{|c|c|c|c|c|c|c|c|}
\hline \multirow{4}{*}{ Characteristics of newborns ${ }^{a}$} & \multicolumn{6}{|c|}{ Place of delivery } & \multirow{4}{*}{$\underset{p^{\mathrm{d}}}{\text { Value }}$} \\
\hline & \multicolumn{2}{|c|}{ Hospitals with NITU ${ }^{\mathrm{b}}$} & \multicolumn{2}{|c|}{ Hospitals without NITU } & \multicolumn{2}{|c|}{ Home/In transit } & \\
\hline & $\mathbf{n}$ & $\%$ & $\mathbf{n}$ & $\%$ & $\mathbf{n}$ & $\%$ & \\
\hline & 342 & 63.7 & 176 & 32.8 & 19 & 3.5 & \\
\hline Race/Color & & & & & & & 0.007 \\
\hline White & 294 & 54.7 & 167 & 31.1 & 12 & 2.2 & \\
\hline Mixed & 42 & 7.8 & 12 & 2.2 & 3 & 0.5 & \\
\hline Negro & 5 & 0.9 & 4 & 0.7 & 3 & 0.5 & \\
\hline Asiatic & 2 & 0.4 & 2 & 0.4 & - & - & \\
\hline Indigenous & - & - & 3 & 0.6 & 1 & 0.2 & \\
\hline Gender & & & & & & & 0.221 \\
\hline Male & 190 & 35.4 & 105 & 19.5 & 10 & 1.8 & \\
\hline Female & 151 & 28.1 & 71 & 13.2 & 9 & 1.7 & \\
\hline Type of delivery & & & & & & & 0.000 \\
\hline Vaginal & 169 & 31.5 & 87 & 16.2 & 19 & 100.0 & \\
\hline Caesarean section & 173 & 32.2 & 89 & 16.6 & - & - & \\
\hline Weight at birth (g) & & & & & & & 0.000 \\
\hline$\leq 1000$ & 193 & 35.9 & 50 & 9.3 & 10 & 1.8 & \\
\hline $1000-1499$ & 53 & 9.9 & 17 & 3.2 & 3 & 0.6 & \\
\hline $1500-2499$ & 58 & 10.8 & 35 & 6.5 & 1 & 0.2 & \\
\hline$\geq 2500$ & 38 & 7.1 & 74 & 13.8 & 5 & 0.9 & \\
\hline Pregnancy age (weeks) & & & & & & & 0.000 \\
\hline $22-26$ & 170 & 31.6 & 45 & 8.4 & 9 & 1.7 & \\
\hline $27-31$ & 73 & 13.6 & 15 & 2.8 & 5 & 0.9 & \\
\hline $32-36$ & 58 & 10.8 & 36 & 6.7 & 1 & 0.2 & \\
\hline$\geq 37$ & 32 & 6.0 & 77 & 14.3 & 4 & 0.7 & \\
\hline Apgar Score $1^{\text {st }}$ minute & & & & & & & 0.000 \\
\hline Grave asphyxia $(\leq 3)$ & 197 & 36.7 & 78 & 14.5 & 3 & 0.6 & \\
\hline Mild asphyxia (4 - 6) & 78 & 14.5 & 35 & 6.5 & 1 & 0.2 & \\
\hline Without asphyxia ( $\geq 7)$ & 66 & 12.3 & 63 & 11.7 & - & - & \\
\hline Apgar Score $5^{\text {th }}$ minute & & & & & & & 0.007 \\
\hline Grave asphyxia $(\leq 3)$ & 84 & 15.6 & 39 & 7.3 & 2 & 0.4 & \\
\hline Mild asphyxia (4 - 6) & 75 & 14.0 & 38 & 7.0 & 2 & 0.4 & \\
\hline Without asphyxia $(\geq 7)$ & 182 & 33.9 & 99 & 18.4 & - & - & \\
\hline Transference of post-partum NB & 13 & 2.4 & 118 & 22.0 & 6 & 1.1 & 0.333 \\
\hline
\end{tabular}

${ }^{\mathrm{a}}$ All percentages exclude unknown information; ${ }^{\mathrm{b}}$ Hospitals with Maternity and Neonatal Intensity Therapy Unit (NITU); ${ }^{\mathrm{c}}$ Hospitals with Maternity and without Neonatal Intensity Therapy Unit (NITU); 'Value of $p$ according to Pearson's chi-square test. 
to private (41.6\%) and 44.5\% government-run hospitals with maternity but without NITU (22\%). Moreover, 2.4\% of neonates were also transferred from hospitals with maternity and NITU due to unavailability of beds at the moment. It should be underscored that only $4.3 \%$ of total births were term birth and discharged after birth.

It should be underscored that $73.6 \%$ (395) of neonates died within the early neonatal period (0 - 6 days), with a mean age of 4.96 days. Table 3 demonstrates that $65.1 \%$ of neonates who died in the early neonatal period were born in hospitals with maternity and NITU, against $31.1 \%$ who were born in hospitals without intensive therapy. Number of deaths was greater in hospitals with NITU (87.3\%) that that of births. Contrastingly, the number of deaths decreased three fold (10.2\%) in hospitals without NITU when compared to that of births. More than half (8) of recently-born children delivered in the home or in transit were born and died on the spot.

With regard to the late neonatal period, the percentages of births in hospital with NITU (59.9\%) were similar when compared to those during the early neonatal period (65.1\%) but much lower than the number of deaths in hospitals without NITU, respectively $10.6 \%$ and $1.4 \%$. Further, in case of delivery in the home or in transit, $4.2 \%$ of deaths occurred after maternity discharge.

\section{Discussion}

Practically all births occurred in a hospital and approximately 7\% at home or in transit. Birth assistance in hospitals with maternity and NITU, either government-run or private, was higher among older females with better schooling, family income and salaried occupation. Accessibility to the place of birth was not homogeneous in most municipalities and regions reported in other researches since there was no availability in obstetric and neonatal beds for attendance by the BHS network. On the other hand, a greater supply was available within the private network for social groups with a better situation. However, the greatest number of high risk births was concentrated within federal and state health services, consequently, featuring the highest indexes of neonatal mortality, as current research evidences [11]-[16].

Births occurred in hospitals contracted by the BHS network (63.7\%). These hospitals provided obstetric and specialized neonatal attendance and, consequently, the greatest number of extreme premature births (weight $\leq$ 1500 grams and $\leq 32$ weeks of pregnancy) with death later on. Variables provided a statistically significant relationship $(p<0.01)$ with place of birth. Results were similar to those in a research that identified the profile of newly born babies and their mothers and the relationship between early neonatal mortality and hospital complexity and its bonding with the BHS in the metropolitan region of São Paulo, Brazil. The authors registered that the BHS network attended $10.5 \%$ of recently born babies with low weight, whilst the private network attended $7.8 \%$ only [15]. Nevertheless, the prospective and multicenter cohort of live newborns with pregnancy age between 23 and 33 weeks and weighing less than $1500 \mathrm{~g}$ in eight university-run maternities between 2004 and 2005 evidenced that early neonatal intra-hospital death rate in 579 newborns was associated with pregnancy age between 23 and 27 weeks, lack of hypertension in the mother, Apgar Score $0-6$ in the $5^{\text {th }}$ minute, presence of

Table 3. Place of delivery and death related to neonatal component (early and late). Londrina PR Brazil, 2000-2009.

\begin{tabular}{|c|c|c|c|c|c|c|c|}
\hline \multirow{4}{*}{ Variables $^{\mathrm{a}}$} & \multicolumn{4}{|c|}{ Neonatal component } & \multirow{2}{*}{\multicolumn{2}{|c|}{ Total }} & \multirow{4}{*}{$\underset{p^{d}}{\text { Value }}$} \\
\hline & \multicolumn{2}{|c|}{ Early (0 - 6 days) } & \multicolumn{2}{|c|}{ Late (7 - 27 days) } & & & \\
\hline & $\mathbf{n}$ & $\%$ & $\mathbf{n}$ & $\%$ & $\mathbf{n}$ & $\%$ & \\
\hline & 395 & 73.5 & 142 & 26.4 & 537 & 100.0 & \\
\hline \multicolumn{8}{|l|}{ Place of delivery } \\
\hline Hospital with NITU & 257 & 65.1 & 85 & 59.9 & 342 & 63.7 & \\
\hline Hospital without NITU & 123 & 31.1 & 53 & 37.3 & 176 & 32.8 & 0.007 \\
\hline Home/in transit & 15 & 3.8 & 4 & 2.8 & 19 & 3.5 & \\
\hline \multicolumn{8}{|l|}{ Place of death } \\
\hline Hospital with NITU ${ }^{\mathrm{b}}$ & 345 & 87.3 & 134 & 94.4 & 479 & 89.2 & \\
\hline Hospital without NITU & 42 & 10.6 & 2 & 1.4 & 44 & 8.2 & 0.001 \\
\hline Home/in transit & 8 & 2.0 & 6 & 4.2 & 14 & 2.6 & \\
\hline
\end{tabular}

${ }^{\mathrm{a}}$ All percentages exclude unknown information; ${ }^{\mathrm{b}} \mathrm{Hospitals}$ with Maternity and Neonatal Intensive Therapy Unit (NITU); ${ }^{\mathrm{C}}$ Hospitals with Maternity and without Neonatal Intensive Therapy Unit (NITU); ${ }^{d}$ Value of $p$ according to Pearson's chi-square test. 
respiratory distress syndrome and place of birth [13]. Other studies showed that public health service in most Brazilian municipalities coped with the greatest number of high risk births and, therefore, the highest indexes of neonatal mortality [14]-[17].

The public health service for high risk obstetric attendance is very common in many countries. Between 2006 and 2007, most newborns (70.5\%) in a public hospital in Johannesburg, South Africa, weighed less than $1500 \mathrm{~g}$, average $1133 \mathrm{~g}$, with less than 30 weeks of pregnancy, and died during the perinatal period [18]. A multicenter analysis undertaken in eight Latin American countries (Argentina, Brazil, Cuba, Ecuador, Mexico, Nicaragua, Paraguay and Peru) reported that the public hospital was the most employed type of service (72.7\%), in which also featured the highest number of pre-term births and deaths in the neonatal period [19]. Similar evidences could be seen in a neonatal unit in the public regional hospital of Valdivia, Chile [20]. Current analysis also demonstrated that full-term births (weight $\geq 2500$ grams and pregnancy age $\geq 37$ weeks) occurred in public and private hospitals without NITU (42.1\%) which attended low and medium risk pregnancies. It has also been verified that these hospitals attended $38.0 \%$ of newborns below weight (less than 1500 grams) and $34.1 \%$ with a pregnancy age of up to 31 weeks.

It should be emphasized that there are no lack of hospital beds for delivery with the usually risk degree. In fact, $98 \%$ of deliveries occurred in hospitals and $80 \%$ were under medical supervision. The qualification of structure, personnel and hospital attendance process should be evaluated for integral assistance and the subsequent decrease in avoidable deaths [21]. The opportune access to a whole set of obstetric and neonatal interventions, acknowledged for their efficaciousness, warrants the reduction of certain impairments and a higher survival rate of risk-prone newborns for a great percentage of the population. In fact, it is possible to attain a standard compatible with that of the best centers in the world [5]. However, such standard is still the privilege of some private and public services of greater complexity, as a rule, teaching and research institutions which do not have the number of required hospital beds, Consequently, a high percentage of the population lack the due attendance [5]. Current research has shown that $70.1 \%$ of newborns weighing less than 2500 grams (56.6\%) and born in hospitals with NITU, did so in municipality-run school-hospital and 54.9\% weighed less than 1000 grams.

In Florianópolis and São José, in the state of Santa Catarina, Brazil, delivery in private hospitals was considered a protecting factor, whilst delivery in teaching-research hospitals was always taken to be a risk factor. However, after a statistical adjustment of weight at birth ( $\leq 2000$ grams), the later started to be considered a protecting factor [16]. A case-control investigation to identify risk factors in Maceió-AL, Brazil, on mortality rates in less than 28-day-old newborns, revealed that more than $70 \%$ of transferred children were born in private maternities which also attended people hailing from the BHS network. Since this fact indicated greater mortality risks during the neonatal period, a low assistance quality and difficulties in accessing health services of good quality were evidenced [11].

Current analysis showed that almost all deliveries at home or in transit led to death during the early neonatal period. Research on the geographic access to birth in hospitals in Brazilian towns demonstrated that slightly more than $70 \%$ undertake less than $1 \%$ of deliveries in the home. Contrastingly, $40.1 \%$ and $90.9 \%$ are respectively due to northern and southern regions. The greater the distance, the higher is the probability of delivery at home and thus more neonate's mortality risks. The Coefficient of Infant Mortality ranged between 15 per 1000 live births in municipalities with displacement of less than $5 \mathrm{~km}$, and 22 per 1000 live births in municipalities with over $50 \mathrm{~km}$ dislocations [22].

The BHS accounts for two thirds of obstetric and neonatal attendance of medium and high complexity in several Brazilian states. It is actually the main funding agent of health services in the country [15] [17]. It also includes a great concentration of teaching activities with experienced professionals that attend to patients, potentially providing them and to neonates with adequate assistance during delivery [5] [15].

The integrality of health assistance depends on the manner the health services are organized and their function at all levels. They include the promotion and prevention in primary care, passing to secondary care, up to the third care at the most complex level. However, when access to these services is limited, there must be gaps in geographic distribution, availability of human and technological resources, funding, assistance model and information on reference and counter-reference system [1] [5] [14] [22]-[24]. In fact, neonatal mortality may be avoided, in the main, through the acknowledgement of maternal requirements in primary health care services. Consequently, services of high complexity that imply high costs are also avoided [5] [7]. Several authors hold that the integrality of assistance and equal access to all in health services is a utopic ideal in Brazil. This is due 
to the difficulties in guaranteeing quality assistance, in applying the directives of the BHS by municipalities and states and in overcoming the social and economic disparities in the different regions of the country [1] [9] [14] [22]-[24].

Please note that the documents published by the Ministry of Health used in this study has established itself as reliable sources for data collection [1] [9], in particular the Declaration of Live Birth as well as the commitment of the Committee of Professionals who investigate infant deaths. On the other hand, it identified some errors in the completion of these documents, one of the main reasons that limit studies using secondary sources. Although there are such gaps, such particularly relevant study is considered when trying to assess the impact of certain processes that influence the dynamics of the social determinants of population health as a child.

\section{Conclusions}

Results of current research revealed that access to obstetric and neonatal hospital service has increased during the last ten years. This is especially true for pregnant women with the lowest socio-economic conditions; prematurity and perinatal mortality became prevalent; the statistical association between the place of birth and the variables focused in the study has occurred.

There still remains the guarantee of integrality of pre-natal assistance, delivery and newborn through equal policies, with a reduction in neonatal deaths which are still high in current analysis. Further research is required to identify gaps within the different levels of health care to the mother and the neonate so that access inequalities could be eliminated.

\section{Conflict of Interest}

The authors declare that they have no conflict of interest.

\section{References}

[1] Paim, J., Travassos, C., Almeida, C., Bahia, L. and Macinko, J. (2011) The Brazilian Health System: History, Advances and Challenges. Lancet, 377, 1778-1797. http://dx.doi.org/10.1016/S0140-6736(11)60054-8

[2] World Health Organization (WHO) (2010) World Health Statistics 2010: Global Health Indicators. Part II. WHO. http://www.who.int/whosis/whostat/EN WHS10 Full.pdf

[3] Vanderlei, L.C.M., Simões, F.T.P.A., Vidal, A.S. and Frias, P.G. (2010) An Evaluation of the Predictors of Neonatal Death in a Time Series of Live Births in the Northeast Region of Brazil. Revista Brasileira de Saúde Materno Infantil, 10, 449-458. http://www.scielo.br/pdf/rbsmi/v10n4/05.pdf http://dx.doi.org/10.1590/S1519-38292010000400005

[4] Zanini, R.R., Moraes, A.B., Giugliani, E.R.J. and Riboldi, J. (2011) Contextual Determinants of Neonatal Mortality Using Two Analysis Methods, Rio Grande do Sul, Brazil. Revista de Saúde Pública, 45, 79-89.

http://www.scielo.br/pdf/rsp/v45n1/en_1549.pdf http://dx.doi.org/10.1590/S0034-89102011000100009

[5] Oza, S., Lawn, J.E., Hogan, D.R., Mathers, C. and Cousens, S.N. (2015) Neonatal Cause of Death Estimates for the Early and Late Neonatal Periods for 194 Countries: 2000-2013. Bulletin of the World Health Organization, 93, 19-28. http://dx.doi.org/10.2471/BLT.14.139790

[6] Behrman, R.E. and Butler, A.S. (2007) Preterm Birth: Causes, Consequences, and Prevention. Committee on Understanding Premature Birth and Assuring Healthy Outcomes. National Academy of Sciences. http://www.nap.edu/catalog/11622.html

[7] Vidal, S.A. (2008) Challenges, Costs and Consequences of Perinatal Morbimortality. Revista Brasileira de Saúde Materno Infantil, 8, 9-10. http://www.scielo.br/pdf/rbsmi/v8n1/01.pdf http://dx.doi.org/10.1590/S1519-38292008000100001

[8] Rattner, D. (2014) Da saúde materno-infantil ao PAISM. Tempus Actas de Saúde Colet, 8, 103-108.

[9] Victora, C.G., Aquino, E.M.L., Leal, M.C., Monteiro, C.A., Barros, F.C. and Szwarcwald, C.L. (2011) Maternal and Child Health in Brazil: Progress and Challenges. Lancet, 377, 1863-1876. http://dx.doi.org/10.1016/S0140-6736(11)60138-4

[10] Figueiredo, P.P., Lunardi-Filho, W.D., Lunardi, V.L. and Pimpão, F.D. (2012) Infant Mortality and Prenatal Care: Contributions of the Clinic in the Light of Canguilhem and Foucault. Revista Latino-Americana de Enfermagem, 20, 201-210. http://www.scielo.br/pdf/rlae/v20n1/26.pdf 
http://dx.doi.org/10.1590/S0104-11692012000100026

[11] Kassar, S.B., Melo, A.M.C., Coutinho, S.B., Lima, M.C. and Lira, P.I.C. (2013) Determinants of Neonatal Death with Emphasis on Health Care during Pregnancy, Childbirth and Reproductive History. Journal of Pediatrics, 89, 269-277. http://dx.doi.org/10.1016/i.jped.2012.11.005

[12] Melo, E.C.P., Knupp, V.M.A.O., Oliveira, R.B. and Tonini, T. (2007) The Peregrination of the Pregnants in Rio de Janeiro City: Deaths and Births Profile. Revista da Escola de Enfermagem da USP, 41, 804-809. http://dx.doi.org/10.1590/S0080-62342007000500011

[13] Almeida, M.F.B., Guinsburg, R., Martinez, F.E., Procianoy, R.S., Leone, C.R., Marba, S.T.M., et al. (2008) Perinatal Factors Associated with Early Deaths of Preterm Infants Born in Brazilian Network on Neonatal Research Centers. Jornal de Pediatria, 84, 300-307. http://www.scielo.br/pdf/jped/v84n4/en_v84n4a04.pdf

[14] Martins, E.F., Rezende, E.M., Almeida, M.C.M. and Lana, F.C.F. (2013) Perinatal Mortality and Socio-Spatial Inequalities. The Revista Latino-Americana de Enfermagem, 21, 1062-1070. http://www.scielo.br/pdf/rlae/v21n5/0104-1169-rlae-21-05-1062.pdf

[15] Silva, Z.P., Almeida, M.F., Ortiz, L.P., Alencar, G.P., Alencar, A.P., Schoeps, D., et al. (2010) Early Neonatal Mortality According to Level of Hospital Complexity in Greater Metropolitan São Paulo, Brazil. Cadernos de Saúde Pública, 26, 123-134. http://www.scielo.br/pdf/csp/v26n1/13.pdf http://dx.doi.org/10.1590/S0102-311X2010000100013

[16] Pinheiro, C.E.A., Peres, M.A. and d’Orsi, E. (2010) Increased Survival among Lower-Birthweight Children in Southern Brazil. Revista de Saúde Pública, 44, 776-784. http://www.scielo.br/pdf/rsp/v44n5/en_1654.pdf http://dx.doi.org/10.1590/S0034-89102010005000031

[17] Malta, D.C., Duarte, E.C., Cortez, J.J.E., Almeida, M.F., Sardinha, L.M.V., Macário, E.M., et al. (2010) Avoidable Causes of Infant Mortality in Brazil, 1997-2006: Contributions to Performance Evaluation of the Unified National Health System. Cadernos de Saúde Pública, 26, 481-491. http://www.scielo.br/pdf/csp/v26n3/06.pdf http://dx.doi.org/10.1590/S0102-311X2010000300006

[18] Ballot, D.E., Chirwa, T.F. and Cooper, P.A. (2010) Determinants of Survival in Very Low Birth Weight Neonates in a Public Sector Hospital in Johannesburg. BMC Pediatrics, 10, 30. http://dx.doi.org/10.1186/1471-2431-10-30

[19] Souza, J.P., Cecatti, J.G., Faundes, A., Morais, S.S., Villar, J., Carroli, G., et al. (2010) Maternal near Miss and Maternal Death in the World Health Organization's 2005 Global Survey on Maternal and Perinatal Health. Bulletin of the World Health Organization, 88, 113-119. http://dx.doi.org/10.2471/BLT.08.057828

[20] Barría-Pailaquilén, R.M., Mendoza-Maldonado, Y., Urrutia-Toro, Y., Castro-Mora, C. and Santander-Manríquez, G. (2011) Trends in Infant Mortality Rate and Mortality for Neonates Born at Less than 32 Weeks and with Very Low Birth Weight. The Revista Latino-Americana de Enfermagem, 19, 977-984. http://www.scielo.br/pdf/rlae/v19n4/17.pdf

[21] Lansky, S. (2010) Quality and Integral Health Care for Women and Children Management in the Public Healthcare System of Belo Horizonte: The Experience of the Perinatal Committee. Revista Tempus-Actas de Saúde Coletiva, 4, 191-199.

[22] Almeida, W.S. and Szwarcwald, C.L. (2012) Infant Mortality and Geographic Access to Childbirth in Brazilian Municipalities. Revista de Saúde Pública, 46, 68-76. http://www.scielo.br/pdf/rsp/v46n1/en 3106.pdf http://dx.doi.org/10.1590/S0034-89102012005000003

[23] Fleury, S. (2011) Unfair Inequalities: The Health Care Counter Right. Psicologia \& Sociedade, 23, 45-52. http://www.scielo.br/pdf/psoc/v23nspe/a07v23nspe.pdf http://dx.doi.org/10.1590/S0102-71822011000400007

[24] Oliveira, G.S., Lima, M.C.B.M., Lyra, C.O., Oliveira, A.G.R.C. and Ferreira, M.A.F. (2013) The Spatial Inequality of Neonatal Mortality in Brazil: 2006 to 2010. Ciência \& Saúde Coletiva, 18, 2431-41.

http://www.scielo.br/pdf/csc/v18n8/28.pdf http://dx.doi.org/10.1590/S1413-81232013000800028 